\title{
Journey Mapping the User Experience
}

\section{Sue Samson, Kim Granath, and Adrienne Alger*}

\begin{abstract}
This journey-mapping pilot study was designed to determine whether journey mapping is an effective method to enhance the student experience of using the library by assessing our services from their point of view. Journey mapping plots a process or service to produce a visual representation of a library transaction-from the point at which the student accesses a service to its final resolution. Service scenarios are identified, and maps are produced that reflect the journey from the student's point of view. The student map is then compared to an "ideal" journey, and the differences are used to explore changes that would improve the service experience.
\end{abstract}

The phrase "The customer is always right" was originally used in 1909 by the founder of Selfridges department store in London. It is typically used by businesses to describe a service ecology designed to convince customers that they will get good service and to empower employees to give customers the service they expect. A century later, academic institutions are rethinking higher education in terms of students as valued customers. In the case of both business and academia, using a service lens to rethink and redesign operations provides a distinct methodology to enhance the user experience. In academic libraries, good service assessment takes the time to identify the sequence users must experience to accomplish essential library activities that meet their research and learning needs. Librarians can use this knowledge to inform changes that most effectively improve those customer experiences.

Academic libraries develop services and collections to serve their primary constituencies of students, faculty, and staff. Students often enter the library physically or via the library website with an assignment at hand and the need for relevant information and resources within a critical timeframe. Faculty and staff need library resources primarily for instruction, research, or grant writing and face similar time constraints. These library users encounter a service ecology that encompasses a combination of personnel, policies, and complexities of both physical and Internet access.

One method of assessing library services and access is journey mapping, also called service blueprinting, a methodology that uses library experiences and touchpoints at which a student comes into contact with the service. ${ }^{1}$ The use of journey mapping is

* Sue Samson is Library Instruction Coordinator, Kim Granath is Head of Information and Research Services Division, and Adrienne Alger is eLearning and Instructional Technology Librarian, all in Mansfield Library at University of Montana; e-mail: sue.samson@umontana.edu, kim.granath@umontana.edu, adrienne. alger@umontana.edu. (2017 Sue Samson, Kim Granath, and Adrienne Alger, Attribution-NonCommercial (http://creativecommons.org/licenses/by-nc/4.0/) CC BY-NC. 
based on an innovative approach to rethink higher education recently reported from the Center for American Progress. ${ }^{2}$ This study examines a new way of viewing the academic library experience, one that reimagines educational offerings and services from the student's point of view. Researchers partnered with students to learn about and eliminate student pain points at the library as they navigate their academic careers. Working with library staff, another goal of the project was to embed the recognition of fail points automatically into our processes.

\section{Literature Review}

Journey mapping and service blueprinting have been used in medicine ${ }^{3}$ and business ${ }^{4}$ for many years as a model for analyzing customer pathways to identify difficulties in service provision. A broad view of using service blueprinting to rethink higher education is summarized by Ostrom et al. in 2011, who focus on the idea of a service lens that views students as customers and state: “...the student experience becomes the central focus upon which the structure, capabilities, and resources of higher education institutions are brought to bear and aligned." 5 They emphasize that this technique facilitates collaboration among stakeholders, highlights the physical evidence that exists from the customer's point of view, and incorporates students as co-creators in their education. Specifically, they use two examples to show how blueprinting can be useful in higher education: the redesign of a course from face-to-face to online and the elimination of pain points in the financial aid process.

With a focus specifically on academic libraries, Marquez and Downey present an excellent introduction to service design as a holistic assessment methodology of library services. ${ }^{6}$ Importantly, service design is a cocreative and user-centered approach to understanding and refining services. Its toolkit includes ethnography, cocreation, journey maps, and blueprinting with an emphasis on the entire ecology of the delivery of service. Its central purpose is to serve users based on the perspective of the user and how services interconnect as a whole.

Several recent studies adapt the use of journey mapping or service blueprinting in academic libraries. With the introduction in the United Kingdom of the Customer Service Excellence standard in 2010, many U.K. academic libraries have sought and gained accreditation using customer journey mapping. Andrews and Eade evaluated the effectiveness of the mapping methodology in engaging students, implications for staff resources, and the identification of service improvements. ${ }^{7}$ They provide a thorough description of a journey-mapping pilot project along with the outcomes and learning points.

In the United States, Bell has championed the opportunities that blueprinting provides for leveraging improvements in higher education and in academic libraries specifically. ${ }^{8}$ Recognizing the debate that develops over the idea that higher education should be run as a business or that students are customers, he states: "From the community member's perspective, the best designed library is one that is easy to use, convenient and satisfies their basic expectations for delivering quality resources and attentive customer service." 9

More recently, Pretlow and Sobel define and describe the process of service blueprinting and the methodology they used as part of a universitywide service-blueprinting project. ${ }^{10}$ Based on user feedback collected by online, written, and in-person methods, a library task force with representatives from all departments identified the library's biggest fail points. The task force then selected one of these fail points, student desktop computing, and began the process of establishing a journey map with a goal of improving this service. Project management software was implemented to track and assign individual staff to particular aspects of service improvement. They emphasize 
that one of the outcomes of this process was that "staff began recognizing fail points in other services."11

\section{Methodology}

This pilot study was designed to determine whether journey mapping is an effective method to enhance the student experience of using the library by assessing our services from their point of view. It implements journey mapping, a methodology that uses library experiences and touchpoints, points at which a student comes into contact with the service. ${ }^{12}$ Journey mapping plots a process or service to produce a visual representation of a library transaction - from the point at which the student accesses a service to its final resolution. Service scenarios are identified, and maps are produced that reflect the journey from the student's point of view. The student map is then compared to an "ideal" journey, and the differences are used to explore changes that would improve the service experience. Finally, as part of the journey-mapping methodology, the data gathered was used to improve services where possible and, based on these successes, to design a more complete journey-mapping study that is focused specifically on the library's web presence using a greater number of student participants.

Scenarios included in this project were divided into six checkpoints based on recommendations by Schmidt and Etches. ${ }^{13}$ These checkpoints are: Physical Space; Service Points; Policies and Customer Service; Signage and Wayfinding; Online Presence; and Using the Library. The scenarios were completed by three student interns enrolled in "LSCI 498, Internship: Careers in Leadership," to complete the in-service portion of their enrollment. These students self-selected this 3-credit class to learn about the profession of librarianship and included a first-year, second-year, and third-year student. They completed the scenarios, mapped the process by using data collection forms to record each transaction, evaluated each transaction of the journeys on a scale of 1-5, and participated in an end-of-semester focus group meeting to further analyze their journeys. Participants were asked not to discuss the scenarios among themselves but were encouraged to use anyone or anything connected to the library for assistance.

The following specific instructions were provided to the interns as part of their course syllabus:

Each intern will be responsible for completing 10 scenarios during the semester. A specific data collection form will be used to record the steps needed to complete each scenario. These forms may be completed in paper or electronic format and must be submitted by the due date.

Procedures to follow for each scenario:

- Describe each step of the process.

- Rate your personal success in completing each step on a scale of 1-5:

$\square \quad 1=$ unsuccessful

ㅁ 2 = not very successful

$\square \quad 3$ = somewhat successful

4 = almost successful

ㄷ 5 = successful.

- Record your personal reactions to the experiences you encounter as you complete the scenario.

- Use any and all resources at your disposal to complete these scenarios with one exception. Do not confer with each other.

All interns will participate in a focus group at the end of the semester to analyze the data collection and make recommendations on how access to library services and resources can be improved. 
In addition, a survey was distributed to all library employees who work at the Information Center at the main campus. This survey was also based on the checkpoints identified by Schmidt and Etches ${ }^{14}$ and was designed to identify staff perceptions of the same aspects of the library that the students were exploring. The goal of the survey was to compare staff perceptions of services with user experiences of these same services.

\section{Findings and Recommendations}

The ten selected scenarios are included in table 1, along with the identification of their checkpoints, and the averaged intern ratings for each. Based on the ratings, the primary stress points for library users were noted in the following scenarios: locate a specific article, acquire a book, and send a chat query. Although no scenarios received the highest rating, those with the highest scores were: charge a cell phone, find a quiet study area, and use the main search box. Detailed analyses of four scenarios are described in this section, and their accompanying journey maps are diagrammed in figures 1-4. The illustrated journey maps document the scenario; identify the expected journey; and use color-coded symbols to identify pain points, highlights, successes, and lack of success. As part of this pilot project, these scenarios were selected as representative of the effectiveness of the methodology, the subsequent analysis, and the implementation of the recommendations.

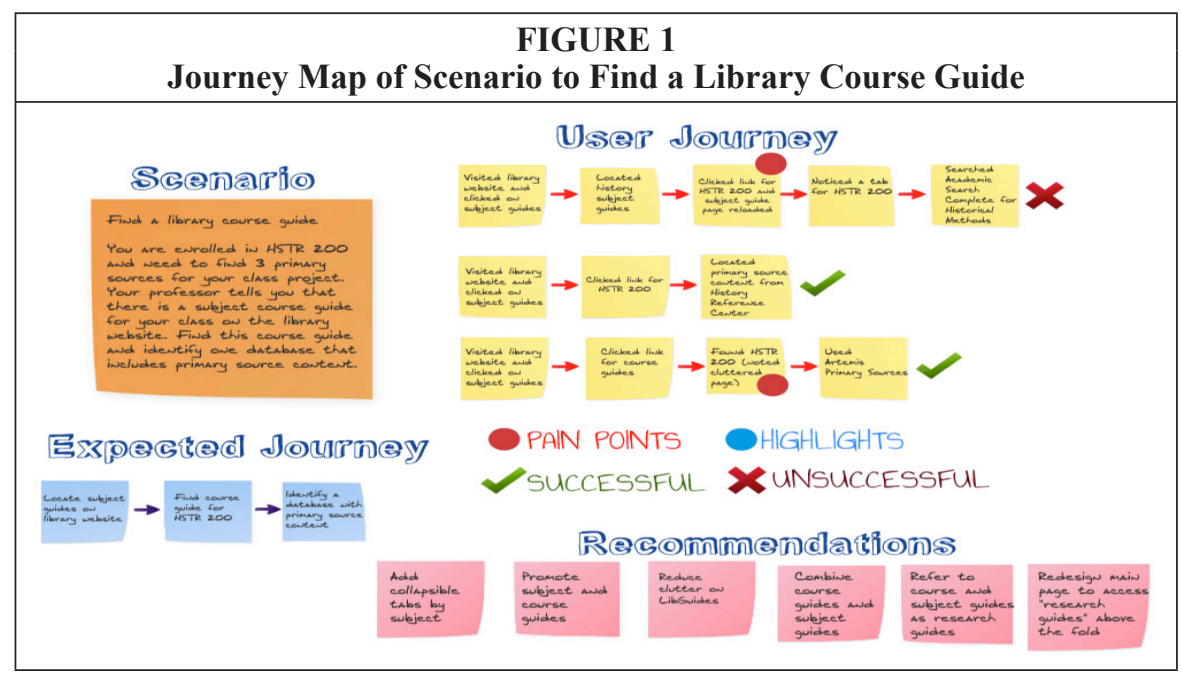

\section{Scenario: Find a library course guide (Figure 1)}

You are enrolled in HSTR 200, Introduction to Historical Methods, and need to find 3 primary sources for your class project. Your professor tells you that there is a subject course guide for your class on the library website that will help you find primary source materials. Find this course guide (record the web address) and identify one database that includes primary source content (record the name of the database).

This scenario addressed the checkpoints of Online Presence and Using the Library. Averaged scores of the interns were 4.3 on a 5.0 scale. In reviewing their data collection forms and during the focus group discussion, the two main findings were:

- Course guides are easily confused with subject guides; and 
- In the example provided, users had difficulty in differentiating guides within a set of subject guides.

Our LibGuides implementation included the terminology of Subject Guides and Course Guides. These needed to be selected by identifying the academic department or unit for the class or subject. The data collection forms and the focus group discussions identified that terminology was clearly confusing to the students. The following recommendations resulted from the analysis:

- Implement the use of collapsible tabs on LibGuides, which was completed as part of an upgrade. Combine Course Guides and Subject Guides into one set of guides, which was completed.

- Change terminology of Course and Subject Guides to Research Guides, which was completed.

- Relocate the Research Guides tab on the main website to a more prominent location, which is in process as part of a web page redesign.

- Promote research guides through instructors and web site marketing opportunities, which is also in process as part of a new marketing initiative.

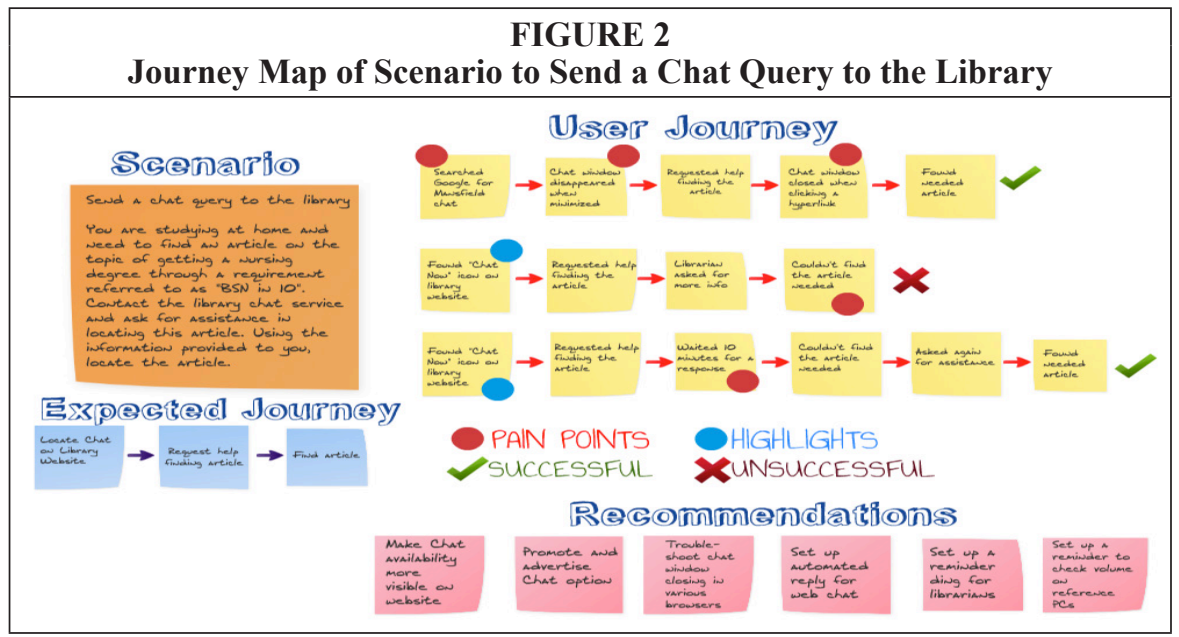

\section{Scenario: Send a chat query to the library (Figure 2)}

You are studying at home and need to find an article on the topic of getting a nursing degree through a requirement referred to as "BSN in 10." Your paper is due tomorrow, and you have not been able to find an article. Contact the library chat service between the hours of 8:00am to 9:00pm Monday through Thursday, or 8:00am to 6:00pm Friday, and ask for assistance in locating this article. Make the following request: "I need a nursing article about bsn in 10. How can I find that?" Using the information provided to you, locate the article.

This scenario addressed the checkpoints of Online Presence, Service Points, and Policies and Customer Service. The averaged intern ratings for this scenario were 3.6 on a 5.0 scale. Analysis of the data collection forms and the focus group discussions identified three primary findings.

- Locating the chat service on the website was difficult; one user found it using a Google search.

- Mechanics of chat were difficult in Chrome because the chat window would disappear when another tab was selected. 
- One user experienced a service delay and was not successful in getting the needed article.

The chat service in use at the time of the journey-mapping research had been in place for a number of years without recent review. The recommendations that came as a result of this study encouraged the staff to make a change to a new chat service. The new service addresses almost every recommendation:

- Make option to chat more visible on the website. The widget is now larger and triggers are in place on primary research pages to encourage questions.

- Determine why the chat window closes in Chrome. The new chat service stays open with all browsers.

- Either make link invisible when service not available or use red/green colors to indicate availability. Straightforward text now indicates that librarians are online for chat or are offline and will take e-mail queries.

- Create autoreplies for times when a response cannot be sent immediately. These automatic replies are part of the new chat service.

The new chat service has had interesting results. In addition to including the first four recommendations of this project, chat usage has increased by 464 percent (comparing data from autumn semester of 2014 to autumn semester of 2015) and, while detailed analysis is yet to be completed, it appears that the complexity of the questions and the audience responding to the new chat widget have charted new territory for chat services at our library.

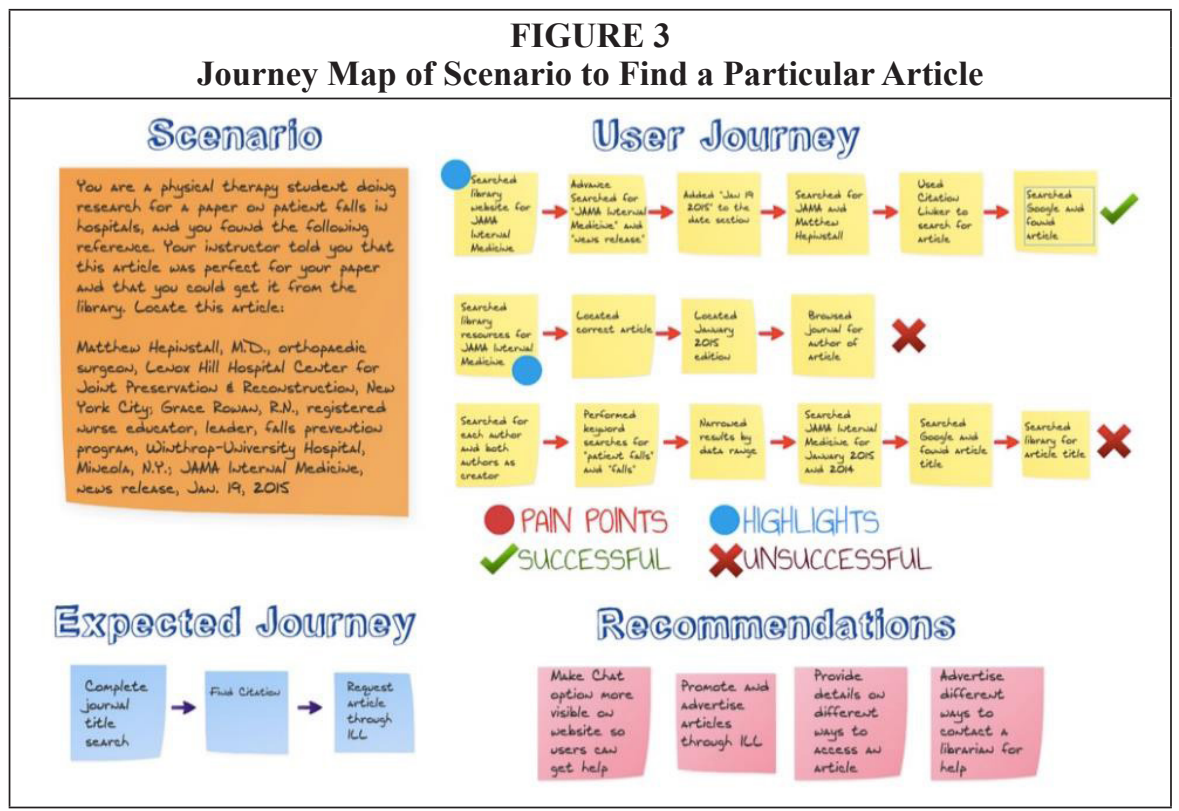

\section{Scenario: Locate this article (Figure 3)}

You are a physical therapy student doing research for a paper on patient falls in hospitals, and you found the following reference. Your instructor told you that this article was perfect for your paper and that you could get it from the library. Locate this article:

- SOURCES: Matthew Hepinstall, M.D., orthopaedic surgeon, Lenox Hill Hospital Center for Joint Preservation \& Reconstruction, New York City; Grace Rowan, R.N., 
registered nurse educator, leader, falls prevention program, Winthrop-University Hospital, Mineola, N.Y.; JAMA Internal Medicine, news release, Jan. 19, 2015

This scenario addresses the checkpoints of Online Presence, Using the Library, Service Points, and Policies and Customer Service. The averaged intern ratings for this scenario were 2.3 on a 5.0 scale, the lowest of all of the scenario ratings. Based on a review of the data collection forms and the focus group discussions, stress points were definitely identified.

- Only one user found the article.

- No users thought to use Interlibrary Loan to retrieve the article.

- No users requested assistance from staff at the reference desk.

The findings in this scenario were surprising for the researchers and fostered the most complex recommendations. The participants had used Interlibrary Loan to acquire books in a previous scenario but did not adapt the use of that service for acquiring an article. More surprising was the fact that, when faced with the inability to find the article, no one asked for assistance. These services are such an integral part of our operations - Interlibrary Loan and reference desk assistance - that it was very alarming to discover how many students must not make use of them. The recommendations are all focused on marketing and awareness.

- Advertise ways to contact a librarian on every web page. The new chat service partially addresses this.

- Provide a pop-up on select pages that state: "Can't get the article you need?" and then provide all the ways you can access an article.

- Advertise Interlibrary Loan as one method for getting articles not available in the library.

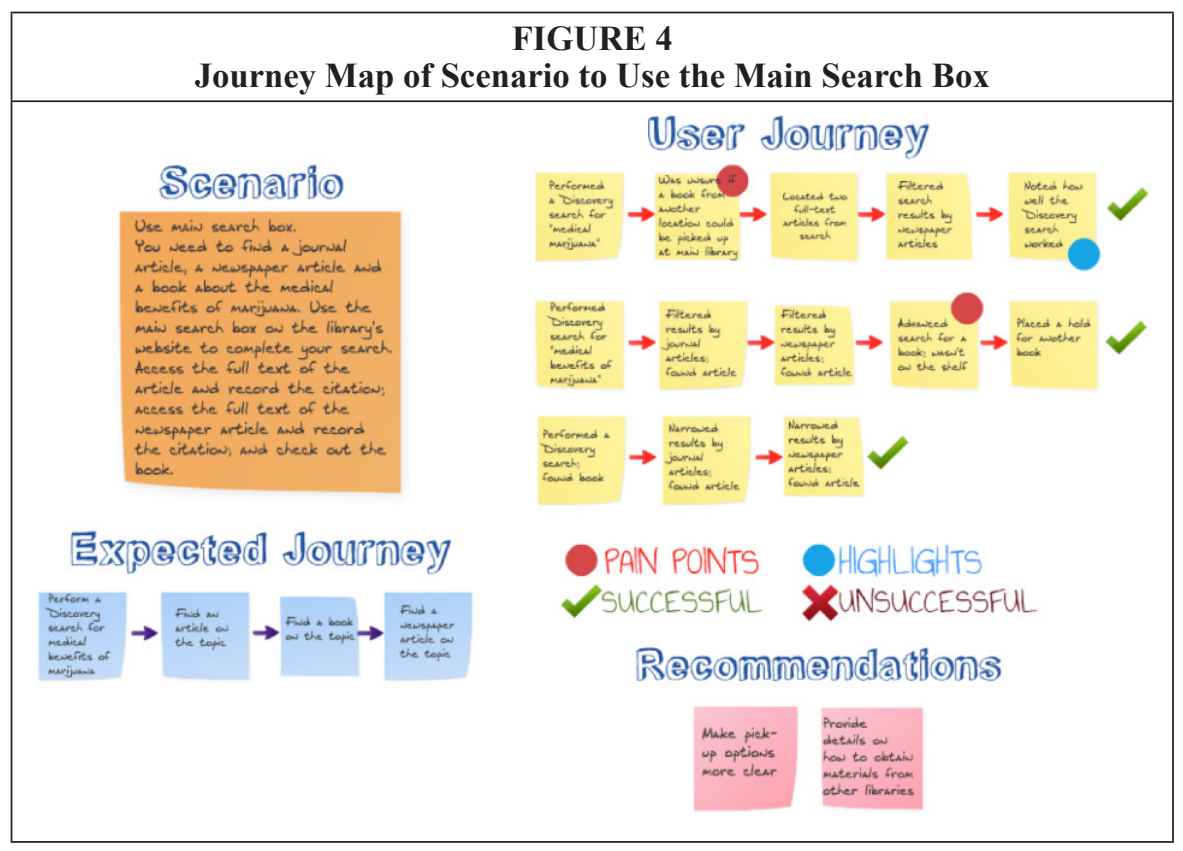

\section{Scenario: Use main discovery search box (Figure 4)}

You need to find a journal article, a newspaper article, and a book about the medical benefits of marijuana. Use the main search box on the library's website to complete your 
search. Access the full text of the article and record the citation; access the full text of the newspaper article and record the citation; and check out the book.

This scenario addressed the checkpoints of Online Presence and Policies and Customer Service. The average score of the participants was 4.4 on a 5.0 scale, one of the highest rated scenarios. Combining a review of the data collection forms and the focus group discussions resulted in the following findings.

- The Discovery search worked well for two of the users who easily entered search terms and narrowed the search to identify books, journal articles, and newspaper articles.

- One user did not see the book option.

- Two users found the link to citation to more easily complete that portion of the scenario.

- One user wondered if a book available in a branch library could be sent to the main library.

One primary recommendation resulted from this analysis.

- Provide notification in the catalog and in the Discovery service that books can be retrieved from affiliate libraries.

This scenario provided substantive data that the Discovery search feature is working effectively.

Detailed analysis of the remaining six scenarios provided excellent opportunities to identify those services and facilities, both in-person and online, that worked well and that needed fixes. Frequently those fixes were easily made. For example, students reserving study rooms with equipment were not always provided the bag of equipment accessories when they checked out the key, nor were they always immediately able to find the equipment when they entered the room. Pop-ups in the circulation module now serve as reminders to check out the accessories along with the key, and instructions for locating the equipment are provided as well.

More complex issues were identified in a scenario when the students needed to locate six journal articles using a subject-specific database, open an account using a bibliographic management tool, save the articles, and format the citations using APA style. While the averaged rating of the process was 4.2 on a 5.0 scale, detailed analysis discovered multiple levels of difficulty in completing this process from beginning to end. The students located articles that satisfied their understanding of the assignment. However, in a review of the data collection forms, the researchers identified issues in the use of bibliographic management tools and in understanding of the library term "subject-specific databases." The recommendations for this scenario will require work with the vendor, collaboration with technical support, and a redefinition of library terminology by our instruction librarians.

\section{Usability Rubric Survey}

Another aspect of this journey-mapping project was the distribution of a usability survey to all staff working as a part of the Information Center at the main campus library. The goal of the survey was to compare staff perceptions of services with user experiences of these same services.

Of the 30 potential participants, 27 completed the survey with a response rate of 90.0 percent (see figures $5-10$ ).

A tested usability rubric (Schmidt and Etches, 2014) was distributed to all library staff providing service at the Information Center on the main campus. Details of the survey results are graphically displayed in figures 5-10. A rating of 3.0 or less on a 5.0 scale was selected by researchers to identify those areas of library services that staff 


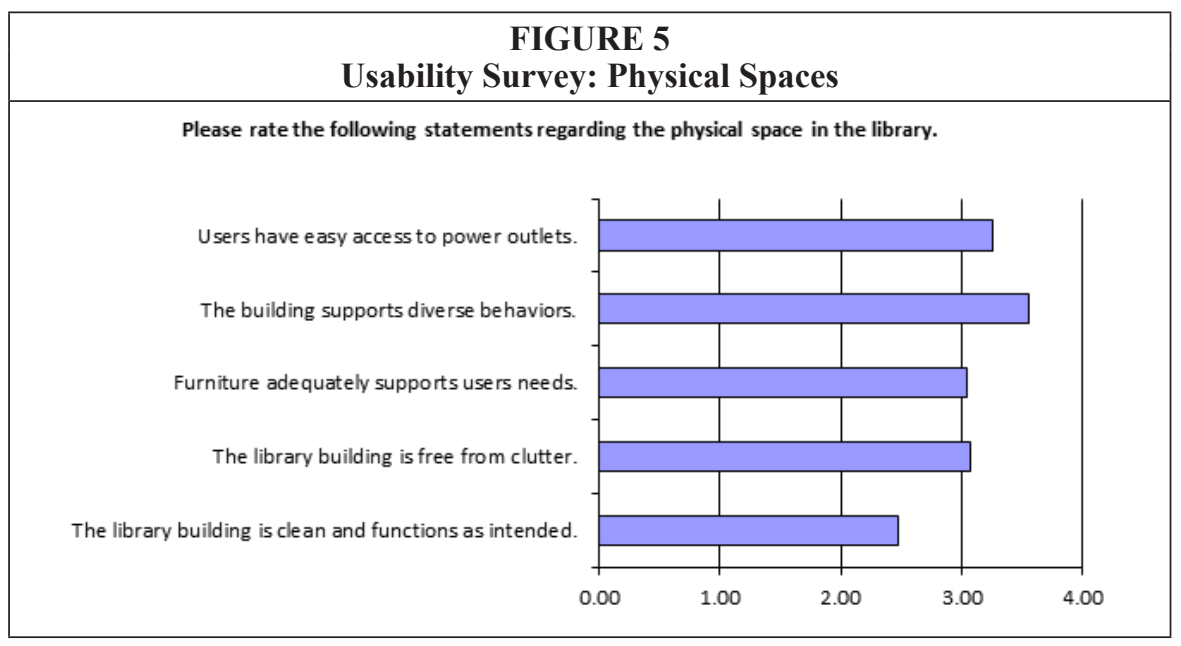

consider more and less successful. A review of the data across all measures revealed 3.0 as an average breaking point that could serve as a reasonable benchmark for purposes of this analysis.

Questions regarding Physical Spaces (figure 5) identified "The library building is clean and functions as intended" with a low score of 2.48 and "The building supports diverse behaviors" as the highest score of 3.50. All statements regarding Service Points (figure 6) received scores at 3.0 or higher. "Service desks adjust to changing needs" just exceeded the 3.0 marker with a score of 3.11 .

With two exceptions, every statement in the section on Policies and Customer Service (figure 7) received a low score. "There is as little policy as possible" (2.07) and "Library policies empower staff" (2.26) were the lowest scoring statements. "Service is consistent across the organization" (2.70), "Library has a unified service philosophy" (2.81), and "Service is consistent across department and modalities" (2.85) were all below the 3.0 acceptable scoring. Finally, "Library staff members know and live the library's service philosophy" (3.0) and "Staff members are friendly and genuinely want to help" (4.11) received the highest scores.

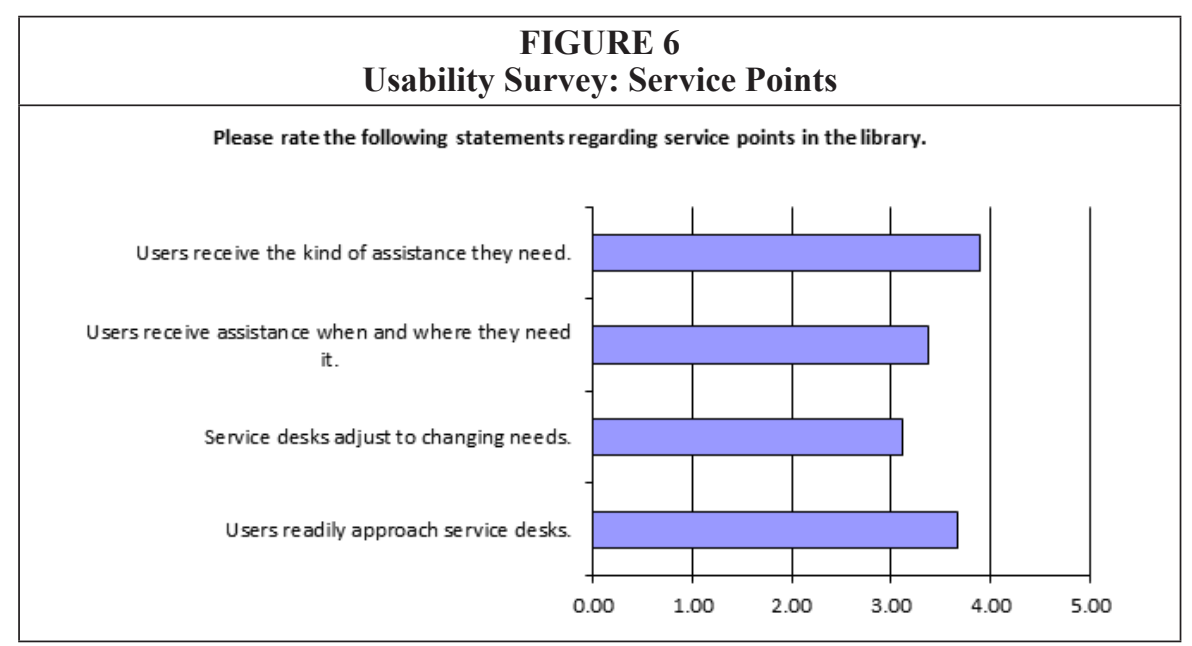




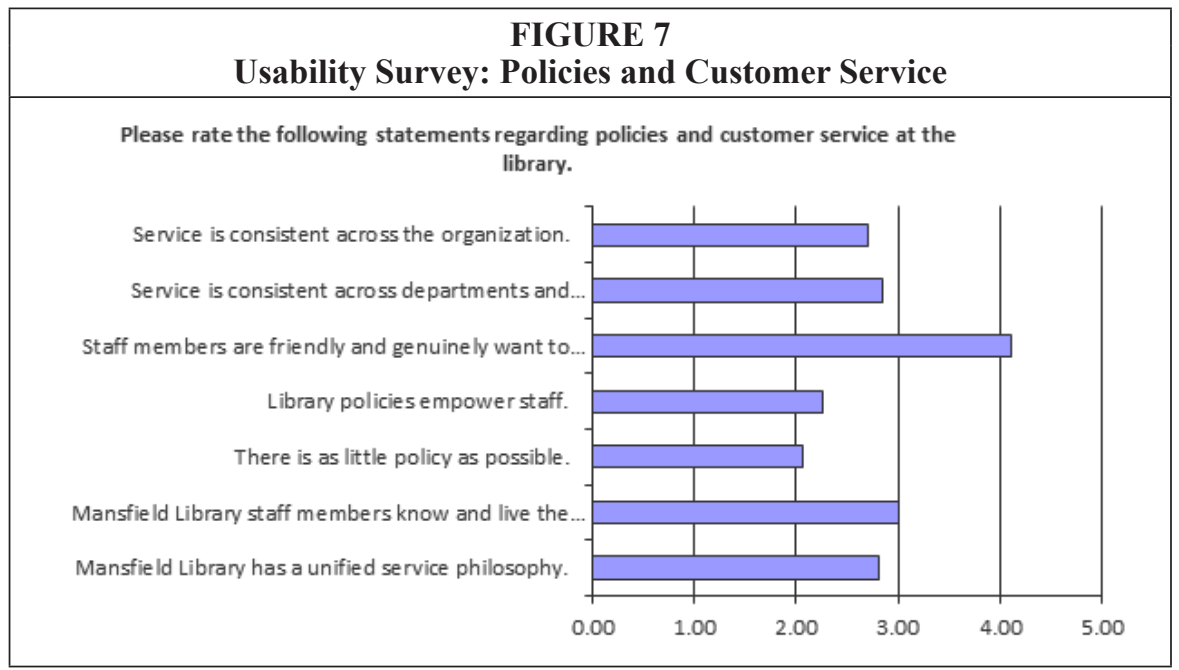

With only one exception, all the statements about Signage and Wayfinding (figure 8) were low. The highest score (3.37) was for "Regulatory signs are written in a plain, polite, and friendly manner." All remaining statements in this section received low scores: "First-time visitors can easily locate all parts of the library" (2.07); "There are as few signs as possible" (2.15); "There are no paper signs taped to walls, doors, tables, computers, or any other surface" (2.15); "Library cards contain useful information and employ the library's visual language" (2.19); "All signage uses the same visual languages" (2.48); "The library has a brand manual that is consistent with the principles of graphic design" (2.52); and "Different types of signs are visually distinct" (2.74).

All statements regarding Online Presence (figure 9) were lower than 3.0 and ranged from 2.63 to 2.89. Arranged by score, the statements included: "Users can easily search for library items and place holds" (2.63); "Website is easy to use on all devices" (2.70); "Users can easily accomplish critical tasks" (2.74); “The library uses social media tools

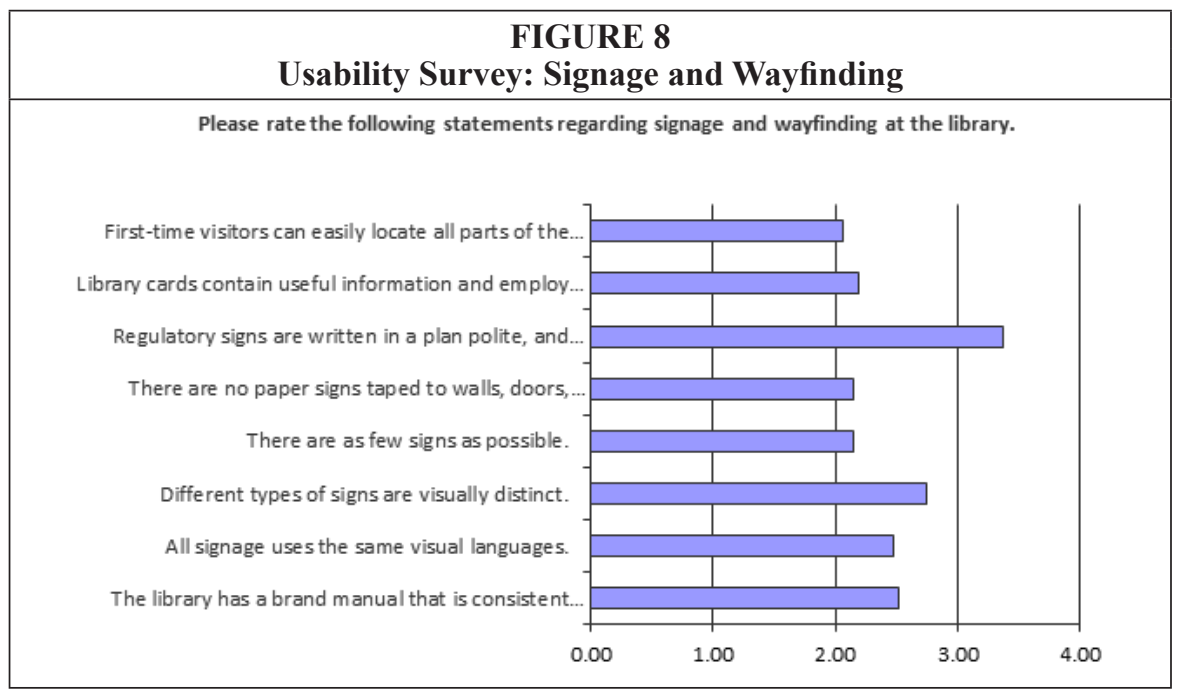



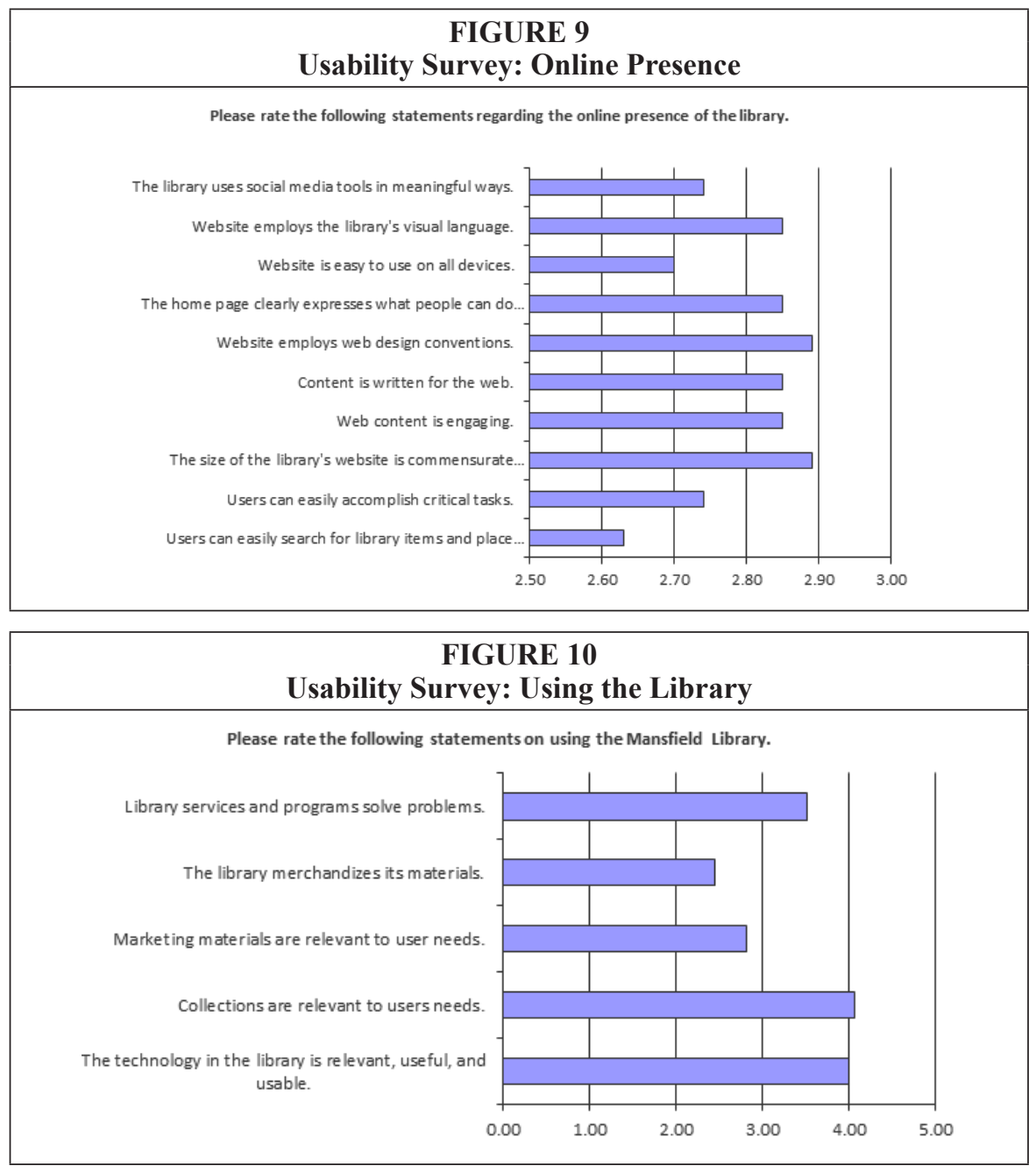

in meaningful ways" (2.74); "Web content is engaging" (2.85); “Content is written for the web" (2.85); "The home page clearly expresses what people can do on the library's website" (2.85); "Website employs the library's visual language" (2.85); "The size of the library's website is commensurate with the amount of effort that we can devote to it" (2.89); and "Website employs web design conventions" (2.89).

Of the five statements based on Using the Library (figure 10), two scored below 3.0: "The library merchandizes its materials" (2.44) and "Marketing materials are relevant to user needs" (2.81). The other statements received more favorable ratings: "Library services and programs solve problems" (3.52); "The technology in the library is relevant, useful, and usable" (4.00); and "Collections are relevant to users' needs" (4.07).

\section{Discussion}

This pilot project underscored the value of journey mapping as a methodology to review and enhance library services. The combination of student journals of their scenarios on data collection forms and the focus group discussions readily revealed the stress points. As a result of the documentation, problematic interactions were easily identified for 
remedy as noted in the section on findings and recommendations. Another interesting aspect of this study was that many stress points could be resolved with rapid action and minor adjustments. For the more complicated pain points, the data collected provided a sound basis for moving forward methodically to resolve these issues.

Collecting data from the student experience also removed that ever-present good intention of library service providers to base policies and services on our own expectations of what students ought to do when using the library. Rather, the focus was immediately one of accepting what the students actually do to process a research or library use activity from their own range of experience. The interns who participated in this pilot project ranged from first-year to third-year students, so their experiences and perspectives nicely complemented our user base. The data gathered provided very specific information for recalibrating both online and in-building services.

The data collected from the staff usability survey also complemented the student data. Researchers mapped the usability survey statements to the journey-mapping scenarios to compare staff ratings with student findings. For example, Scenario 7 asks users to locate an article and maps to the survey statements about Online Presence: "The home page clearly expresses what people can do on the library website" (2.85), "Users can easily accomplish critical tasks" (2.74), and "Users can easily search for library items and place holds" (2.63). The averaged student rating for this scenario was 2.3, which was consistent with the averaged staff survey response. Several recommendations were made and changes were implemented in this area as a result of the study. Scenario 6 asked students to find a place in the library to charge their cell phone, which they were all able to do, and the average rating was 4.4 ; the usability survey statements that map well to this scenario were "Users have easy access to power outlets" (3.26) and "The technology in the library is relevant, useful and usable" (4.00). In this case, the students rated these checkpoints higher than staff, resulting in few recommendations.

Presentations of the data gathered were presented to small working groups within the library both to share the findings and to encourage others to reimagine their services by focusing on the user experience. After several presentations, the intent of the researchers is to redistribute the staff usability survey to identify any changes in perceptions as a result of the current project.

The results of this pilot study, particularly the increased usage of the new chat platform implemented as a direct result of the researcher's findings, indicate that journey mapping can be an effective method of enhancing user experience. A limitation of the study was the small sample size of participant interns. The researchers have secured funds to conduct a follow-up study to be conducted in autumn semester 2016, with a larger group of student participants that focuses specifically on the library's web presence.

\section{Conclusions}

The scope of this study was informative, and the process guided researchers to make recommendations to the appropriate units and to the Library Administration Advisory Board to improve the experience of our users. While the findings were completed in a single academic library with a small sample size and are not generalizable, both minor and more involved changes are either already completed or were set into motion to improve user experience at different checkpoints. Although some units chose not to make changes based on our recommendations, this exemplifies the evolutionary nature of reexamining the library through the user experience. This pilot study reinforces how a journey-mapping methodology can inform decision making with the intention to identify and to break down barriers for users and improve their experience across different units of the library. 


\section{Further Research}

Most importantly, the researchers encourage other librarians to replicate the journeymapping methodology in their own institutions. Based on the findings of this study, further journey-mapping research could focus on specific identified checkpoints in greater depth; a journey-mapping study of the library's web presence is being designed at this time. Other studies could recruit more students from a wider range of prior library expertise to complete scenarios by offering incentives and/or limiting the amount of work required of a participant. Another interesting aspect would be to compare journey-mapping scenarios between first-year and upper-division students. An iterative approach to this model could inform researchers of persistent pain points as well as service improvements after each cycle of study, recommendations, and new implementations.

\section{Notes}

1. Judith Andrews and Eleanor Eade, "Listening to Students: Customer Journey Mapping at Birmingham City University Library and Learning Resources," New Review of Academic Librarianship 19, no. 2 (2014): 161-77.

2. Amy L. Ostrom, Mary Jo Bitner, and Kevin A. Burkhard, "Leveraging Service Blueprinting to Rethink Higher Education," Center for American Progress (2011): 1-69.

3. Johanna I. Westbrook, Enrico W. Coiera, A. Sophie Gosling, and Jeffrey Braithwaite, "Critical Incidents and Journey Mapping as Techniques to Evaluate the Impact of Online Evidence Retrieval Systems on Health Care Delivery and Patient Outcomes," International Journal of Medical Informatics 76, no. 2/3 (2007): 234-45.

4. G.L. Shostack, "Understanding Services Through Blueprinting," Advances in Services Marketing and Management 1 (1984): 6-23.

5. Ostrom, Bitner, and Burkhard, "Leveraging Service Blueprinting," 2.

6. Joe Marquez and Annie Downey, "Service Design: An Introduction to a Holistic Assessment Methodology of Library Services," Weave: Journal of Library User Experience 1, no. 2 (2015).

7. Andrews and Eade, "Listening to Students," 162.

8. Steven Bell, "Blueprinting for Better Library Customer Service I From the Bell Tower," Library Journal Academic Newswire (e-newsletter), June 14, 2012, http://lj.libraryjournal.com/2012/06/ opinion/steven-bell/blueprinting-for-better-library-customer-service-from-the-bell-tower/.

9. Steven Bell, "Transforming the Library Starts with Mapping the Journey" (keynote speech presented at the American Library Association Virtual Conference, July 25, 2013).

10. Cassi Pretlow and Karen Sobel, "Rethinking Library Service: Improving the User Experience with Service Blueprinting," Public Services Quarterly 11, no. 1 (2015): 1-12.

11. Ibid., 11.

12. Andrews and Eade, "Listening to Students," 167.

13. Aaron Schmidt and Amanda Etches, Useful, Usable, Desirable: Applying User Experience Design to Your Library (Chicago: American Library Association, 2014), 168.

14. Ibid. 